\title{
Serum total homocysteine and coronary heart disease: prospective study in middle aged men
}

P H Whincup, H Refsum, I J Perry, R Morris, M Walker, L Lennon, A Thomson, P M Ueland, S B J Ebrahim

\begin{abstract}
Objectives-To examine the prospective relation between total homocysteine and major coronary heart disease events.

Design-A nested case-control study carried out within the British regional heart study, a prospective investigation of cardiovascular disease in men aged 40-59 years at entry. Serum total homocysteine concentrations were analysed retrospectively and blindly in baseline samples from 386 cases who had a myocardial infarct during 12.8 years of follow up and from 454 controls, frequency matched by age and town.
\end{abstract}

Results-Geometric mean serum total homocysteine was slightly higher in cases $(14.2 \mu \mathrm{mol} / \mathrm{l})$ than in controls $(13.5 \mu \mathrm{mol} /$ 1), a proportional difference of $5.5 \%(95 \%$ confidence interval (CI) $-\mathbf{0 . 0 2 \%}$ to $10.8 \%$, $p=0.06)$. Age adjusted risk of myocardial infarction increased weakly with log total homocysteine concentration; a 1 SD increase in log total homocysteine (equivalent to a $47 \%$ increase in total homocysteine) was associated with an increase in odds of myocardial infarction of 1.15 $(95 \%$ CI 1.00 to $1.32 ; p=0.05)$. The relation was particularly marked in the top fifth of the total homocysteine distribution (values $>16.5 \mu \mathrm{mol} / 1$ ), which had an odds ratio of 1.77 (95\% CI 1.28 to 2.42$)$ compared with lower levels. Adjustment for other risk factors had little effect on these findings. Total homocysteine concentrations more than $16.5 \mu \mathrm{mol} / 1$ accounted for $13 \%$ of the attributable risk of myocardial infarction in this study population. Serum total homocysteine among control subjects varied between towns and was correlated with town standardised mortality ratios for coronary heart disease $(r=0.43, p=0.08)$.

Conclusions-Serum total homocysteine is prospectively related to increased coronary risk and may also be related to geographical variation in coronary risk within Britain. These results strengthen the case for trials of total homocysteine reduction with folate.

(Heart 1999;82:448-454)

Keywords: coronary heart disease; homocysteine; epidemiology

Homocystinuria is a rare genetic disorder involving impaired metabolism of the sulphur containing amino acid, homocysteine. It is associated with markedly raised blood concentrations of total homocysteine and with a high risk of thromboembolic events, including myocardial infarction, in adolescence and even in childhood. ${ }^{12}$ A moderate rise in total homocysteine concentration is also associated with increased risk of arteriosclerotic vascular events and venous thrombosis. ${ }^{3-5}$ In the general population, moderate hyperhomocysteinaemia is a common condition which usually results from deficiency of nutritional factors required for homocysteine metabolism (folate, vitamin B-12, and possibly vitamin B-6) and from mild genetic defects. ${ }^{67}$

In an overview of 17 studies (both retrospective and prospective) examining the relation between total homocysteine and coronary heart disease, Boushey et al found that 14 showed a positive association, with an increased odds of 1.6 for men and 1.8 for women for each $5 \mu \mathrm{mol} / 1$ increase in total homocysteine. ${ }^{4}$ However, most of the studies reviewed were retrospective; only three ${ }^{8-10}$ were based on blood samples collected before the onset of clinical disease. Moreover, the results of these prospective studies, and three published subsequently, ${ }^{11-13}$ were not consistent with one another. ${ }^{14}$ In the US physicians' health study cohort, the risk of myocardial infarction was increased in the top $5 \%$ of the total homocysteine distribution. ${ }^{8}$ Consistent graded associations between serum total homocysteine concentration and risk of coronary events were found both in the Tromsø study ${ }^{10}$ and the British BUPA cohort, ${ }^{13}$ while a graded relation between total homocysteine level and all cause mortality was observed in a study of Norwegian men and women with established coronary artery disease. ${ }^{12}$ In contrast, in neither the Finnish North Karelia project ${ }^{9}$ nor the American multiple risk factor intervention trial $(\text { MRFIT })^{11}$ was any association observed between total homocysteine and coronary heart disease.

We have examined the relation between serum total homocysteine concentration and risk of major coronary heart disease events, looking both for graded and non-linear associations, using a nested case-control study design within the British regional heart study cohort. The strengths of such a design are its prospective nature and, in this case, its ability to take a wide range of potential confounding factors into account. An association between serum total homocysteine and risk of stroke has already been demonstrated in an earlier, smaller, nested case-control study within this study population. ${ }^{15} 16$ 


\section{Methods}

STUDY DESIGN AND ANALYSIS

A nested case-control study was conducted within the British regional heart study, a longitudinal study of cardiovascular disease in 7735 middle aged men aged 40-59 years initially examined in 1978-1980. Approval of local research ethics committees was obtained. Participants were randomly selected from the age-sex registers of representative group General Practices in each of 24 towns across England, Wales, and Scotland (response rate $78 \%$ ). The criteria for selecting the towns, the general practices, and the subjects, as well as the methods of data collection, have been presented in detail elsewhere. ${ }^{17-20}$ The cases were first major coronary heart disease events, fatal and non-fatal, occurring between the beginning of follow up and December 1991 in 18 study towns in which serum aliquots had been routinely stored, but automatically excluding a random subsample selected for earlier casecontrol studies. ${ }^{151621}$ Cases with pre-existing coronary heart disease were not excluded, but the influence of these subjects on the results has been specifically examined. Controls were subjects who survived to the end of the study period free from incident myocardial infarction and stroke. They were randomly selected, with frequency matching to cases by town and by age group (in five year age bands); reserve controls were identified in case serum samples could not be identified or were inadequate. The study was designed to be of sufficient size to detect an increase in the odds of first myocardial infarction of 1.5 in the top half of the total homocysteine distribution compared with the bottom half with $80 \%$ power at $\mathrm{p}=0.05$.

DATA COLLECTION

Baseline

At entry to the study, a nurse administered a questionnaire to each man on occupation, smoking habits, alcohol intake, habitual physical activity, and medical history, including a modified WHO (Rose) chest pain questionnaire. ${ }^{22}$ Social class was based on the longest held occupation, using the Registrar General's 1971 classification and including a separate category for armed forces. Cigarette smoking was classified into six groups, current smokers (1-19, 20, 21-39, 40+/day), exsmokers, and never smokers. Alcohol intake was classified into five groups: none, occasional ( $<1$ unit/week), light (1-15 units/week), moderate (16-42 units/week), and heavy ( $>42$ units/week). A physical activity score with six levels (inactive, occasional, light, moderate, moderately vigorous, vigorous) was derived from the physical activity questionnaire. ${ }^{23}$ Body mass index (weight $/$ height $^{2}$ ) was used as an index of relative weight. Blood pressure was measured twice with the subject seated using a London School of Hygiene sphygmomanometer. The mean of the two readings was used in the analysis; all blood pressure readings were adjusted for observer variation within each town. Forced expiratory volume in one second $\left(\mathrm{FEV}_{1}\right)$ was measured twice with the subject seated using a spirometer; data are based on the maximum value and have been standardised for height. An orthogonal three lead ECG was recorded. A non-fasting blood sample was collected for laboratory analysis; in the last 18 towns serum was stored at $-20^{\circ} \mathrm{C}$ for later analyses.

\section{Follow up}

All men were followed up for all cause mortality (through National Health Service Central Registers) and for cardiovascular morbidity (through reports from general practitioners, supplemented by regular reviews of general practice records) to December 1991 (mean follow up 12.8 years). Fewer than $1 \%$ of subjects were lost to follow up over this period.

\section{CLASSIFICATION OF HEART DISEASE}

Presence of pre-existing coronary heart disease This was based on one or more of the following: definite angina; possible or definite myocardial infarction on Rose questionnaire; recall of a doctor's previous diagnosis of angina or myocardial infarction; or ECG evidence of possible or definite myocardial ischaemia or infarction. ${ }^{18}$

\section{Incident myocardial infarction}

Fatal cases of ischaemic heart disease were ascertained on the basis of a death certificate with ICD-9 codes $410-414$ as the underlying cause of death. Non-fatal myocardial infarction was diagnosed in accordance with WHO criteria $^{20}$ on the basis of at least two of the following: severe prolonged chest pain, ECG evidence of myocardial infarction, cardiac enzyme changes. Death occurring within 28 days of the onset of symptoms led to reclassification as a fatal episode.

BLOOD COLLECTION AND LABORATORY METHODS Non-fasting venous blood samples were obtained at the baseline examination between 08:30 and 18:30. Serum was separated on site within an hour of venepuncture, stored at $4^{\circ} \mathrm{C}$ until the following day and at $-20^{\circ} \mathrm{C}$ thereafter. Serum total homocysteine was determined, blind to case/control status, in the department of clinical biology, University of Bergen, after a storage period of 17-19 years, during which the samples had been thawed twice. A modification of an automated assay was used, based on pre-column derivatisation with monobromobimane, followed by reverse phase high performance liquid chromatography with fluorescence detection. ${ }^{24}{ }^{25}$ The between-day coefficient of variation is less than $5 \%$. Replicate measurements were routinely performed; all values presented are based on the mean of two values. Methods of analysis of blood lipids, urate, and packed cell volume have been described elsewhere. ${ }^{26}$

STATISTICAL ANALYSIS

Statistical analyses were carried out using the SAS statistical package. Serum total homocysteine concentrations followed a log normal distribution and were accordingly log transformed for analysis; differences between cases 
Table 1 Characteristics of cases and controls

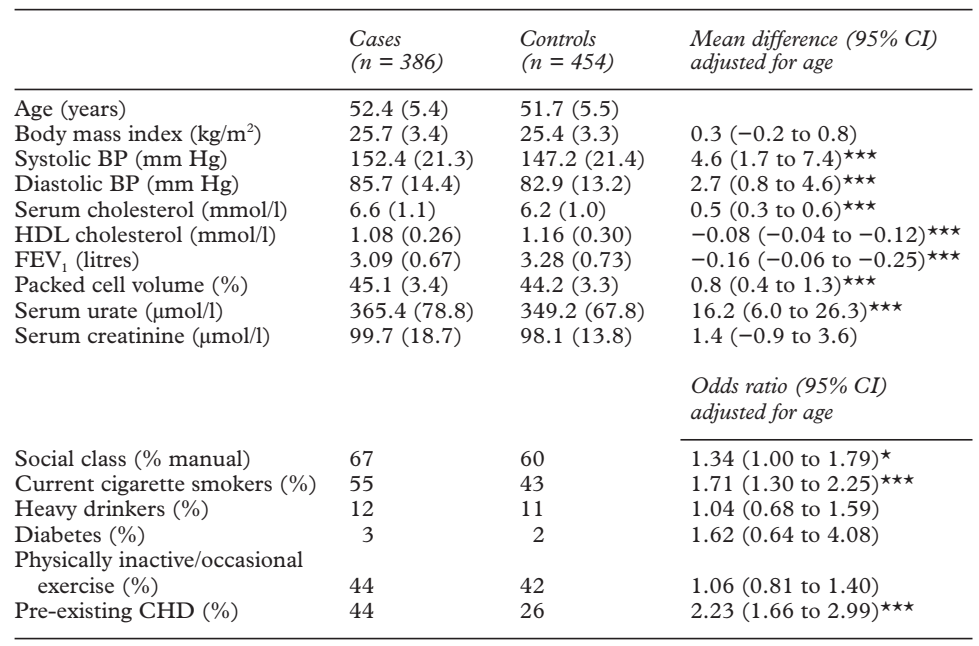

Values are mean (SD) or $\%$.

${ }^{\star} \mathrm{p}<0.05 ; \star \star \star \star \mathrm{p}<0.001$.

$\mathrm{BP}$, blood pressure; $\mathrm{CHD}$, coronary heart disease; $\mathrm{CI}$, confidence interval; $\mathrm{FEV}_{1}$, forced expiratory volume in one second; HDL, high density lipoprotein.

and controls were examined using the $t$ statistic. Analyses of total homocysteine fifths or centiles are based on the total homocysteine distribution among control subjects. Comparisons of frequencies have been carried out using $\chi^{2}$ tests or Fisher's exact test as appropriate. Standard linear regression techniques using PROC GLM were used to obtain age adjusted mean values. Adjusted odds ratios were obtained using PROC LOGIST. Age, systolic pressure, blood glucose, $\mathrm{FEV}_{1}$, and cholesterol were fitted as continuous variables (fitting each at five levels made no difference to the estimated effect of total homocysteine). Smoking (six levels), alcohol intake (five levels), social class (seven levels), and town (18 levels) were fitted using dummy variables. For descriptive purposes towns were grouped into three geographical regions (southern England, northern England, and Scotland); southern and northern England were separated by a line joining the Wash and the Bristol Channel. The population attributable risk fraction (PARF) is the proportion of total risk $(3 r \times p)$ which is attributable to the specific risk factor, $(r-1) \times$ $p$, where $r$ is the relative risk and $p$ the proportion of the population exposed.

\section{Results}

CHARACTERISTICS OF CASES AND CONTROLS

Of 459 cases sought, 386 samples ( $84 \%)$ were located and analysed, and $172(45 \%)$ of these were from fatal cases. Of 454 controls sought, 424 samples (93\%) were located and analysed, with 30 replacements. The characteristics of cases and controls are shown in table 1. Cases were slightly older than controls, and (even after age adjustment) had significantly higher mean values of blood pressure, cholesterol, packed cell volume, and urate, and lower mean values of high density lipoprotein cholesterol and $\mathrm{FEV}_{1}$ than the control subjects. As expected, the prevalences of cigarette smoking, manual social class, and pre-existing coronary heart disease were markedly higher in cases than controls. The distributions of total homo- cysteine in cases and controls are shown in fig 1 . From the 20 th centile upwards, total homocysteine concentrations for cases were higher than those for controls; the difference became increasingly marked in the upper part of the distribution. However, the geometric mean total homocysteine concentration in cases $(14.2 \mu \mathrm{mol} / \mathrm{l})$ was only slightly higher than that in controls $(13.7 \mu \mathrm{mol} / \mathrm{l})$, and the proportional difference was of marginal statistical significance $(5.5 \%, 95 \%$ confidence interval (CI) $-0.02 \%$ to $10.8 \%, \mathrm{p}=0.06)$.

TOTAL HOMOCYSTEINE AND CARDIOVASCULAR RISK FACTORS AMONG CONTROL SUBJECTS

The relations between serum total homocysteine and cardiovascular risk factors among control subjects are summarised in tables 2 and 3. Total homocysteine was positively associated with packed cell volume and inversely with $\mathrm{FEV}_{1}$; no consistent associations with age, creatinine, blood pressure, or lipids were apparent in this study population. Total homocysteine was strongly related to region, but not to social class, cigarette smoking, heavy alcohol intake, and physical activity. Although total homocysteine concentrations appeared somewhat higher in subjects with diabetes, they were not strongly affected by the presence of preexisting coronary heart disease.

GEOGRAPHICAL VARIATION IN TOTAL

HOMOCYSTEINE AMONG CONTROL SUBJECTS

There was marked geographical variation in geometric mean serum total homocysteine among controls, with the lowest value (11.1 $\mu \mathrm{mol} / \mathrm{l})$ in Bedford and the highest (17.1) in

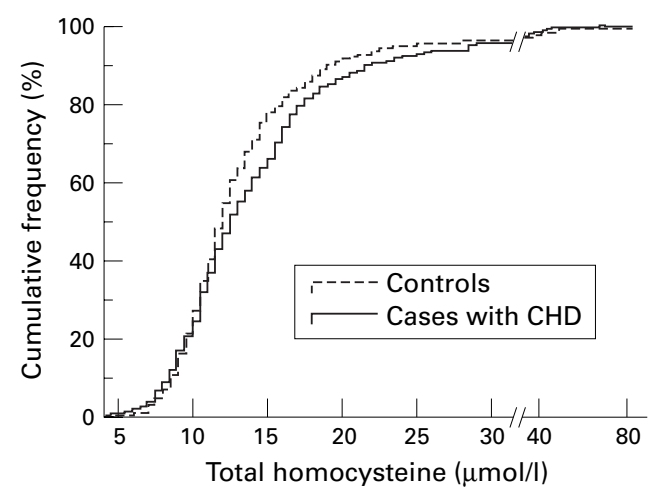

Figure 1 Cumulative frequency plot showing the distribution of total homocysteine concentrations among cases and controls.

Table 2 Correlation between serum total homocysteine and cardiovascular risk factors among control subjects

\begin{tabular}{|c|c|c|}
\hline & $\begin{array}{l}\text { Correlation } \\
\text { coefficient }\end{array}$ & $p$ Value \\
\hline Age (years) & 0.08 & 0.09 \\
\hline Body mass index $\left(\mathrm{kg} / \mathrm{m}^{2}\right)$ & -0.07 & 0.12 \\
\hline Systolic BP (mm Hg) & 0.03 & 0.49 \\
\hline Diastolic BP (mm Hg) & 0.04 & 0.38 \\
\hline Serum cholesterol $(\mathrm{mmol} / \mathrm{l})$ & -0.03 & 0.48 \\
\hline HDL cholesterol $(\mathrm{mmol} / \mathrm{l})$ & 0.04 & 0.38 \\
\hline $\mathrm{FEV}_{1}$ (litres) & -0.13 & 0.006 \\
\hline Packed cell volume (\%) & 0.12 & 0.01 \\
\hline Urate $(\mu \mathrm{mol} / \mathrm{l})$ & 0.06 & 0.17 \\
\hline Creatinine $(\mathrm{mmol} / \mathrm{l})$ & 0.06 & 0.23 \\
\hline
\end{tabular}

$\mathrm{BP}$, blood pressure; $\mathrm{FEV}_{1}$, forced expiratory volume in one second; HDL, high density lipoprotein. 
Table 3 Serum total homocysteine: associations with other factors among control subjects

\begin{tabular}{|c|c|c|c|}
\hline Factor & $n$ & $\begin{array}{l}\text { Geometric mean } \\
\text { total homocysteine } \\
(\mu \text { molll) }\end{array}$ & $p$ Value \\
\hline \multicolumn{4}{|l|}{ Cigarette smoking } \\
\hline Current smoker & 194 & 13.7 & \\
\hline Ex-smoker & 156 & 13.3 & \\
\hline Never smoked & 104 & 13.3 & 0.64 \\
\hline \multicolumn{4}{|l|}{ Alcohol intake } \\
\hline Heavy drinker & 52 & 13.6 & \\
\hline All others & 402 & 13.5 & 0.90 \\
\hline \multicolumn{4}{|l|}{ Physical activity } \\
\hline \multicolumn{4}{|l|}{ Inactive/occasional } \\
\hline All others & 254 & 13.5 & 0.90 \\
\hline \multicolumn{4}{|l|}{ Pre-existing CHD } \\
\hline Present & 116 & 13.9 & \\
\hline Absent & 338 & 13.3 & 0.33 \\
\hline \multicolumn{4}{|l|}{ Diabetes } \\
\hline Present & 8 & 10.5 & \\
\hline Absent & 446 & 13.6 & 0.06 \\
\hline \multicolumn{4}{|l|}{ Social class } \\
\hline Manual & 267 & 13.8 & \\
\hline Non-manual & 175 & 12.9 & 0.10 \\
\hline \multicolumn{4}{|l|}{ Region } \\
\hline Southern England & 115 & 12.7 & \\
\hline Northern England & 258 & 13.3 & \\
\hline Scotland & 81 & 15.5 & 0.0008 \\
\hline
\end{tabular}

CHD, coronary heart disease.

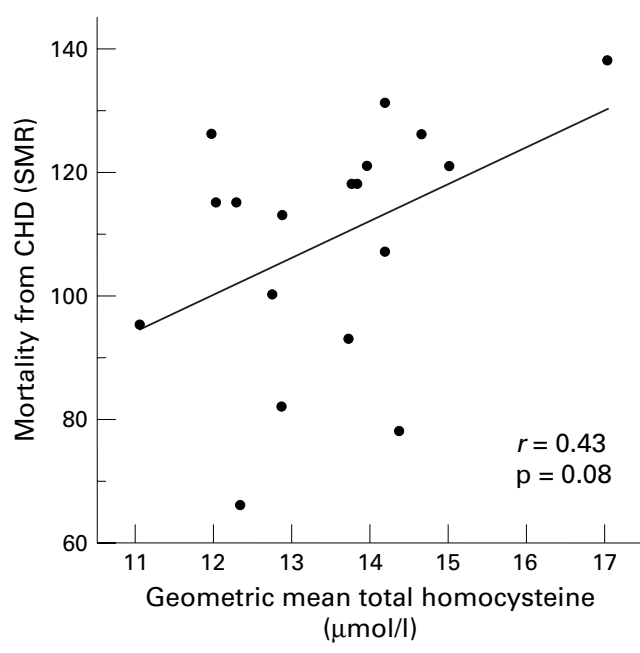

Figure 2 Geometric mean total serum homocysteine in control subjects and standardised mortality ratios (SMR) for ischaemic heart disease (men 35-64 years, 1979-1983), by town.

Ayr. When towns were grouped into major regions, total homocysteine was lowest in southern England, intermediate in northern England, and highest in Scotland (table 3). In an ecological analysis, town geometric mean total homocysteine concentrations among controls were weakly correlated $(r=0.43$, $\mathrm{p}=0.08$ ) with town standardised mortality

Table 4 Relative risk of major coronary heart disease events in each fifth of total homocysteine compared with the first

\begin{tabular}{lllll}
\hline \multirow{2}{*}{$\begin{array}{l}\text { Serum total } \\
\text { homocysteine }(\mu \mathrm{mol} / \mathrm{l})\end{array}$} & \multicolumn{4}{l}{ Odds ratios (95\% confidence intervals) } \\
\cline { 2 - 5 } & $A$ & & & \\
\hline$<10.4$ & 1.00 & $(0.46$ to 1.13$)$ & 1.00 & \\
$10.4-$ & 0.72 & $(0.44$ to 1.09$)$ & 0.77 & $(0.46$ to 1.29$)$ \\
$12.0-$ & 0.69 & $(0.55$ to 1.35$)$ & 0.89 & $(0.41$ to 1.17$)$ \\
$13.5-$ & 0.86 & $(0.94$ to 2.19$)$ & 1.45 & $(0.88$ to 1.50$)$ \\
$16.6-$ & 1.43 & & & \\
\hline
\end{tabular}

A, adjusted for age group, town.

$\mathrm{B}$, adjusted for age group, town, cigarette smoking, systolic blood pressure, serum cholesterol, high density lipoprotein cholesterol, forced expiratory volume in one second, packed cell volume, serum urate, serum creatinine, social class, alcohol intake, physical activity, body mass index. ratios (SMR) for ischaemic heart disease during the five year period 1979 to 1983 (fig 2). A similar pattern of between town variation in total serum homocysteine concentrations was observed among the cases; the values were correlated both with control levels $(r=0.50$, $\mathrm{p}=0.03)$ and, more weakly, with SMR values for ischaemic heart disease $(r=0.35$, $\mathrm{p}=0.15)$.

TOTAL HOMOCYSTEINE AND CORONARY RISK

Log transformed total serum homocysteine showed a positive relation with coronary risk. For each 1 SD increase in log total homocysteine (equivalent to a $47 \%$ rise in total homocysteine concentration), the odds of myocardial infarction increased by 1.15 (95\% CI 1.00 to $1.32 ; \mathrm{p}=0.05)$. When the relation between total serum homocysteine and coronary risk was examined in fifths of the total homocysteine distribution (table 4), the increased risk was entirely in the top fifth (total serum homocysteine $>16.5 \mu \mathrm{mol} / \mathrm{l}$ ), which had an odds ratio of 1.76 (95\% CI 1.28 to 2.43 , $\mathrm{p}=0.0006)$ when compared with the lower four groups together-suggesting a threshold effect in the relation. The odds ratio of a coronary event above the 95th centile of the control total homocysteine distribution (serum total homocysteine $>25.8 \mu \mathrm{mol} / \mathrm{l}$ ) was 1.81 $(95 \%$ CI 1.02 to $3.23, p=0.04)$ when compared with values below the 80th centile of the control total homocysteine distribution. The odds ratio of a coronary event at total homocysteine concentrations $>15.8 \mu \mathrm{mol} / \mathrm{l}$, compared with values $<14.1 \mu \mathrm{mol} / 1$ (a replication of the principal analysis in the US physicians' health study $\left.{ }^{8}\right)$ was $1.76(95 \%$ CI 1.28 to $2.41, \mathrm{p}=0.0005)$.

EFFECT OF ADJUSTMENT FOR CARDIOVASCULAR RISK FACTORS

The effect of adjustment for risk factors was examined in 359 cases and 414 controls with complete risk factor data. Adjustment for all the factors listed in tables 2 and 3 had little effect on the relations between total homocysteine and coronary risk. The increase in odds of a major coronary heart disease event for a $1 \mathrm{SD}$ rise in log total homocysteine (equivalent to a $47 \%$ increase in total homocysteine concentration) remained weak, at 1.17 (95\% CI 0.99 to $1.38 ; \mathrm{p}=0.07)$. The apparently non-linear relation between total homocysteine (fifths) and risk of myocardial infarction was little affected by adjustment (table 4); the adjusted odds ratio in the top fifth (total serum homocysteine $>16.5 \mu \mathrm{mol} / \mathrm{l}$ ) was 1.75 (95\% CI 1.20 to $2.55, \mathrm{p}=0.003$ ) compared with the lower four fifths. The adjusted odds ratio above the 95th centile of the control total homocysteine distribution (serum total homocysteine $>25.8 \mu \mathrm{mol} / \mathrm{l})$ was $2.02(95 \%$ CI 1.02 to $3.99, \mathrm{p}=0.04$ ) compared with values below the 80th centile. The adjusted odds ratio of a coronary event at total homocysteine concentrations of $>15.8 \mu \mathrm{mol} / 1$, compared with values $<14.1 \mu \mathrm{mol} / 1,{ }^{8}$ was 1.76 (95\% CI 1.21 to 2.55 , $\mathrm{p}=0.003)$. 
Table 5 Relative risk of major coronary heart disease events in the top fifth of the total homocysteine distribution: by age group and pre-existing coronary heart disease (CHD)

\begin{tabular}{|c|c|c|}
\hline & Relative risk & $(95 \% C I)$ \\
\hline \multicolumn{3}{|l|}{ Age group (years) } \\
\hline $40-49$ & 2.55 & (1.43 to 4.55$)$ \\
\hline $50-59$ & 1.48 & (1.00 to 2.21 ) \\
\hline Test for difference & $\mathrm{p}=0.13$ & \\
\hline \multicolumn{3}{|l|}{ Pre-existing CHD } \\
\hline Yes & 1.81 & (1.04 to 3.17 ) \\
\hline No & 1.54 & (1.01 to 2.34$)$ \\
\hline Test for difference & $\mathrm{p}=0.62$ & \\
\hline
\end{tabular}

CI, confidence interval.

INFLUENCE OF AGE, PRE-EXISTING CORONARY HEART DISEASE, FATALITY, AND TIMING OF EVENT The relations between total homocysteine and coronary risk were examined separately in younger and older men and in men with and without pre-existing heart disease, comparing the odds ratios for men in the upper fifth of the total homocysteine distribution with those in the lower four fifths (table 5). The relations between total homocysteine and coronary risk appeared somewhat stronger in men aged 40-49 years at baseline, although there was no strong evidence of age interaction. In men without pre-existing disease, the odds ratio was 1.54 (95\% CI 1.01 to 2.34), slightly weaker than in men with pre-existing coronary heart disease, though there was no strong evidence of a difference $(p=0.62)$. The relation between total homocysteine and myocardial infarction appeared similar in fatal cases (odds ratio 1.75, $95 \%$ CI 1.16 to 2.63) and non-fatal cases (odds ratio $1.68,95 \%$ CI 1.15 to 2.47 ). The relation was at least as strong in cases occurring during the second six years of follow up (odds ratio $1.83,95 \%$ CI 1.22 to 2.75 ) as in the first six years (odds ratio $1.66,95 \%$ CI 1.13 to 2.44 ), providing no support for the possibility of a very short term association.

POPULATION ATTRIBUTABLE RISK

Based on the division of total homocysteine concentration into fifths, with increased risk in the top fifth of the control distribution (serum total homocysteine $>16.5 \mu \mathrm{mol} / \mathrm{l}$ ), a raised total homocysteine accounted for $13 \%$ of the attributable risk in this study population both before and after adjustment for other cardiovascular risk factors.

\section{Discussion}

Our results suggest that raised serum total homocysteine is related to an increased risk of major coronary heart disease events in these British men. In these data, the association appears to be non-linear, being confined to the top fifth of the total homocysteine distribution. The association appears to be independent of a wide range of lifestyle and biological factors, including serum creatinine. It is present both in subjects with and without pre-existing coronary heart disease and in both 40-49 and 50-59 year olds, but may be stronger in younger subjects.

A great advantage of the nested case-control study design is that the blood samples on which total homocysteine measurements are based were collected before the onset of coronary heart disease events. This is particularly important because there is evidence that total homocysteine concentrations may rise after myocardial infarction, ${ }^{27}$ making the interpretation of retrospective studies difficult. Although the samples were stored over a long period (17-19 years), there is evidence that total homocysteine concentrations are not markedly affected by long term storage under similar conditions to those in the present study. ${ }^{98}$ Since the storage and handling of case and control samples were identical at all stages, it is unlikely that a biased estimate of the association between total homocysteine and coronary heart disease events has been obtained.

The levels of total homocysteine observed in this study were higher than those in any of the earlier population based prospective studies, including the predominantly professional British population studied in the BUPA cohort. $^{8-1113}$ Since the samples were separated rapidly after collection, this is not likely to be an artefact of sample handling. While the differences may reflect laboratory variation, a recent report has suggested that serum total homocysteine in British adults may be relatively high compared with Swedish subjects. ${ }^{29}$ Such international differences, if confirmed, may be important because of the ecological evidence that total homocysteine concentrations are related to coronary heart disease mortality at the population level. ${ }^{30}$

The results of earlier population based prospective studies examining the relation between total homocysteine and coronary heart disease have been conflicting. ${ }^{8-14}$ Our observations suggest that an association between total homocysteine and coronary risk is likely to be non-linear, a finding consistent with the observations of some earlier investigators. ${ }^{12} 3132$ The threshold total homocysteine concentration at which risk appears to increase in the present study $(>16.5 \mu \mathrm{mol} / \mathrm{l})$ is reasonably close to that reported in the physicians' health study (total homocysteine above $15.8 \mu \mathrm{mol} / 1^{8}$ ). However, only a much larger study would be able to distinguish definitively between a graded and a threshold relation and place the threshold precisely, so the interpretation of these findings should remain cautious. The reason for the negative findings of the North Karelia and MRFIT studies $^{911}$ remains unclear. In the North Karelia project, ${ }^{9}$ the overall design and follow up period (eight years) were very similar to those in our study. While mean total homocysteine concentrations in control subjects in the North Karelia project were lower than those in the British regional heart study men, the $95 \%$ confidence intervals around the odds ratio for a continuous linear relation between total homocysteine and coronary heart disease (0.94 to 1.07) overlapped with those in the present study. The only analysis examining the possibility of a threshold effect in the North Karelia data (an analysis of total homocysteine levels above the 95th centile of the distribution) had little power and wide confidence limits both for 
men (0.56 to 1.95$)$ and women (0.66 to 2.78 ), which again overlap with those in the present study. The age group and total homocysteine concentrations in the MRFIT control subjects were very similar to those in the British regional heart study. ${ }^{11}$ However, most cases (61\%) were fatal events occurring between 11 and 20 years after blood collection. Although our results, based on follow up for over 12 years, do not suggest that the effects of total homocysteine are limited to the first six years of follow up, it is likely that the relation between total homocysteine and coronary heart disease risk is weaker in the second decade of follow up than in the first. Other studies, for example the US physicians study, have observed attenuation of risk even during the first seven years of follow up. ${ }^{33}$ Differences in design and analytical approach, and limitations of statistical power, may therefore account for at least part of the variation in the findings of the different studies. However, it is also possible that differences in nutritional factors (including vitamin supplementation) or genetic factors may modify the strength of relations between total homocysteine and coronary heart disease in the different study populations. In the MRFIT study in particular, the increasing intake of vitamin supplements among the US population occurring during the long follow up period might have played a part in attenuating the total homocysteine-myocardial infarction relation. In contrast, the prevalence of vitamin supplementation in the British regional heart study population remains very low $(<15 \%$ ) (Whincup $\mathrm{PH}$, unpublished data, 1996).

In the present study, the relation between total homocysteine and coronary heart disease appeared to be strongly independent of other cardiovascular risk factors and also of creatinine level, a potential confounding variable $e^{34} 35$ not included in adjustment in many earlier studies. ${ }^{8-11}$ Although total homocysteine has been related to several other risk factors, including cigarette smoking, ${ }^{36}$ this was not the case in the present study, despite the relation between total homocysteine and $\mathrm{FEV}_{1}$ among controls. As in earlier studies, ${ }^{8} 1012$ the total homocysteine-coronary heart disease relation was little affected by adjustment for other coronary risk factors. The relation was somewhat stronger in younger than older men, a finding consistent with, though less marked than, the age differences in the US physicians' health study, in which the odds ratio of the top $5 \%$ of the total homocysteine distribution was 11.0 in men aged less than 60 years, but 2.0 in men aged 60 years or more. ${ }^{8}$ Similarly, in the Troms $\varnothing$ study, the association between total homocysteine and coronary heart disease was slightly stronger among younger subjects $(<53$ years) than among older subjects. This is biologically plausible, given the lower prevalence of other major risk factors among younger men. The present results also suggest that the relation between total homocysteine and coronary heart disease is present both in subjects with and without pre-existing coronary heart disease, although power to detect differences in the total homocysteine-myocardial infarction relation between these groups is limited. Few of the earlier population based prospective studies have been able to examine this issue, because subjects with pre-existing disease were excluded. ${ }^{8911}$ However, our finding that total homocysteine influences coronary heart disease risk among subjects with preexisting coronary heart disease is consistent with, though less strong than, that of a recent prospective study by Nygard et al. ${ }^{12}$

The systematic geographical variation in total homocysteine levels in control subjects is consistent with much more recent data obtained in British older adults (65+ years) in the 1995-6 national diet and nutrition survey, which found a gradient in total homocysteine concentrations of similar direction and magnitude. ${ }^{29}$ The ecological association with coronary heart disease mortality observed, though weak and of limited power, suggests that variations in total homocysteine may contribute to the explanation of geographical variations in coronary risk. The finding would be consistent with the well documented geographical variations in dietary fruit and vegetable intake, and particularly in dietary folate intakes, which have been consistently lower in Scotland than in southern England ${ }^{37}$ However, geographical variations in the frequency of relevant genetic polymorphisms could also play a role in this variation. ${ }^{38}$

\section{CONCLUSION}

Our results suggest that total homocysteine may be making an appreciable contribution to population attributable coronary heart disease risk, at least in men, and could contribute to the explanation of geographical variation in coronary risk within Great Britain. Further studies are needed to examine the contribution of total homocysteine to coronary risk in women, and to define the relative importance of environmental and genetic determinants of total homocysteine in this and other populations. The results strengthen further the case for randomised controlled trials testing the effect of folate supplementation on the risk of coronary heart disease. ${ }^{39}$ The present results suggest that Scotland might be a particularly appropriate setting in which to conduct such a trial.

The British Regional Heart Study Research Group has a programme grant from the British Heart Foundation and is also supported by the Department of Health and the Stroke Association. We would like to acknowledge the contribution of Professor A G Shaper, the original Director of the British Regional Heart Study.

1 Mudd SH, Levy HL, Skovby F. Disorders of transsulfuration. In: Scriver CR, Beaudet AL, Sly WS, Valle D, eds. The metabolic basis of inherited disease. New York: McGraw-Hill, 995:1279-327.

2 Ueland PM, Refsum H. Plasma homocysteine as a risk factor for vascular disease: plasma levels in health, disease and drug therapy. F Lab Clin Med 1989;114:473-501.

3 Refsum H, Ueland PM, Nygard O, Vollset SE. Homocysteine and cardiovascular disease. Anпи Rev Med 1998;49:31-62.

4 Boushey CJ, Beresford SAA, Omenn GS, et al. A quantitative assessment of plasma homocysteine as a risk factor for vascular disease. ҒAMA 1995;274:1049-57.

5 Den Heijer M, Koster T, Blom HJ, et al. Hyperhomocysteinemia as a risk factor for deep vein thrombosis. $N$ cysteinemia as a risk factor

6 Selhub J, Jacques PF, Wilson PWF, et al. Vitamin status and intake as primary determinants of homocysteinemia in an elderly population. $\mathcal{F A M A}$ 1993;270:2693-8. 
7 Stampfer MJ, Malinow MR. Can lowering homocysteine levels reduce cardiovascular risk? N Engl f Med 1995;332: levels redu.

8 Stampfer MJ, Malinow MR, Willett WC, et al. A prospective study of plasma homocyst(e)ine and risk of myocardial infarction in US physicians. $\mathcal{F} A M A 1992 ; 268: 877-81$.

9 Alfthan G, Pekkanen J, Jauhiainen M, et al. Relation of serum homocysteine and lipoprotein(a) concentrations to atherosclerotic disease in a prospective Finnish population based study. Atherosclerosis 1994;106:9-19.

10 Arnesen E, Refsum H, Bonaa KH, et al. Serum total homocysteine and coronary heart disease. Int $\mathcal{f}$ Epidemiol 1995;24:704-9.

11 Evans RW, Shaten BJ, Hempel JD, et al. Homocyst(e)ine and risk of cardiovascular disease in the Multiple Risk Factor Intervention Trial. Arterioscler Thromb Vasc Biol 1997; 17:1947-53.

12 Nygard O, Nordrehaug JE, Refsum $\mathrm{H}$, et al. Plasma homocysteine levels and mortality in patients with coronary cysteine levels and mortality in patients with
artery disease. N Engl f Med 1997;337:230-6.

13 Wald NJ, Watt HC, Law MR, et al. Homocysteine and ischaemic heart disease. Results of a prospective study with implications regarding prevention. Arch Intern Med 1998; implication

14 Danesh J, Lewington S. Plasma homocysteine and coronary heart disease: systematic review of published epidemiological studies. F Cardiovasc Risk 1998;5:229-32.

15 Perry IJ, Refsum H, Morris RW, et al. Prospective study of serum total homocysteine concentration and risk of stroke in middle-aged British men. Lancet 1995;346:1395-8.

16 Perry IJ. Serum total homocysteine concentration and risk of stroke. Lancet 1996;348:1526.

17 Shaper AG, Pocock SJ, Walker M, et al. The British Regional Heart Study: cardiovascular risk factors in middle-aged men in 24 towns. BMF 1981;283:179-86.

18 Phillips AN, Shaper AG, Pocock SJ, et al. The role of risk factors in heart attack occurring in men with pre-existing factors in heart attack occurring in men with pre-exic

19 Walker M, Shaper AG. Follow-up of subjects in prospective studies in general practice. $\mathcal{F} R$ Coll Gen Pract 1984;34:197209.

20 Shaper AG, Pocock SJ, Walker M, et al. Risk factors for ischaemic heart disease: the prospective phase of the British Regional Heart Study. $\mathcal{F}$ Epidemiol Community Health 1985: 39:197-209.

21 Whincup PH, Mendall MA, Perry IJ, et al. Prospective relations between Helicobacter pylori infection, coronary heart disease, and stroke in middle aged men. Heart 1996;75 568-72.

22 Cook DG, Shaper AG, Macfarlane PW. Using WHO (Rose) angina questionnaire in cardiovascular epidemiologica studies. Administration, definition and predictive value. Int f Epidemiol 1989;18:607-13.

23 Shaper AG, Wannamethee G. Physical activity and ischaemic heart disease in middle-aged British men. Br Heart $\mathcal{F}$ 1991;66:384-94.
24 Fiskerstrand T, Refsum H, Kvalheim G, et al. Homocysteine and other thiols in plasma and urine: automated determination and sample stability. Clin Chem 1993;39:263-71.

25 Refsum H, Ueland PM, Svardal AM. Fully automated fluorescence assay for determining total homocysteine in plasma. Clin Chem 1989;35:1921-7.

26 Wannamethee G, Shaper A. Haematocrit: relationships with blood lipids, blood pressure and other cardiovascular risk factors. Thromb Haemost 1994;72:58-64.

27 Egerton W, Silberberg J, Crooks R, et al. Serial measures of plasma homocyst(e)ine after acute myocardial infarction. Am f Cardiol 1996;77:759-61.

28 Israelsson B, Brattstrom L, Refsum H. Homocysteine in frozen plasma samples: a short cut to establish hyperhomocysteinaemia as a risk factor for arteriosclerosis? Scand 7 Lab Invest 1993;53:465-9.

29 Bates CJ, Mansoor MA, van der Pols J, et al. Plasma total homocysteine in a representative sample of 972 British men and women aged 65 and over. Eur $\mathcal{f}$ Clin Nutr 1997;51:691-7.

30 Alfthan G, Ato A, Gey KF. Plasma homocysteine and cardiovascular disease mortality. Lancet 1997;349:397.

31 Pancharuniti N, Lewis CA, Sauberlich HE, et al. Plasma homocyst(e)ine, folate and vitamin B12 concentrations and risk for early onset coronary artery disease. Am $\mathcal{f C l i n}$ Nutr 1994;59:940-8.

32 von Eckardstein A, Malinow MR, Upson B, et al. Effects of age, lipoproteins and hemostatic parameters on the role of homocyst(e)inaemia as a cardiovascular risk factor in men. Arterioscler Thromb 1994;14:460-4.

33 Chasan-Taber L, Selhub J, Rosenberg IH, et al. A prospective study of folate and vitamin $\mathrm{B}_{6}$ and risk of myocardial infarction in US physicians. F Am Coll Nutr 1996:15:13643.

34 Brattstrom L, Lindgren A, Israelsson B, et al. Homocysteine and cysteine: determinants of plasma levels in middle-aged and elderly subjects. F Intern Med 1994;236:633-41.

35 Bostom AG, Lathrop L. Hyperhomocysteinaemia in end stage renal disease: prevalence, aetiology and potential relationship to arteriosclerotic outcomes. Kidney Int 1997; 52:10-20.

36 Nygard O, Vollset SE, Refsum H, et al. Total plasma homocysteine and cardiovascular risk profile: the Hordaland Homocysteine Study. $7 A M A$ 1995;274:1526-33.

37 Ministry of Agriculture, Fisheries and Food. National food survey 1994. London: HMSO, 1996.

38 Gudnason V, Stansbie D, Scott J, et al. C677T (thermolabile alanine/valine) polymorphism in methylenetetrahydrofolate reductase (MTHFR): its frequency and impact on plasma homocysteine concentration in different European populations. Atherosclerosis 1998;136:347-54.

39 Verhoef P, Stampfer MJ, Rimm EB. Folate and coronary heart disease [review]. Curr Opin Lipidol 1998;9:17-22. 